\title{
CUENTOS VIEJOS O DIÁLOGO CON EL UNIVERSO
}

Carlos Rubio Torres ${ }^{1}$

\section{Resumen}

Cuentos viejos es un libro escrito por María Leal de Noguera, publicado en diferentes ediciones entre 1923 y 1945 , que se puede considerar texto fundador de una literatura costarricense dirigida a las jóvenes generaciones. Constituye una colección de cuentos de hadas, que representan un caudal de conocimientos y sabiduría atesorados en muy diversas regiones del orbe. Para demostrar su vigencia, se hace un análisis de uno de los cuentos: "La mano peluda" y se descubre que este texto dialoga con mitos muy antiguos: la historia griega de Eros y Psique y una narración hindú del Panchatantra, en la cual se describe el amor de la ninfa Urvasi y el mortal Pururavas.

Palabras claves: literatura costarricense, literatura infantil, María Leal de Noguera, textos culturales, Psique y Eros, Urvasi y Pururavas.

\section{Abstract}

Cuentos Viejos (Old Tales) a book written by María Leal de Noguera, published in different editions between 1923 and 1945, may be considered a milestone in the foundations of a Costa Rican literature for the younger generations. It is a collection of fairy tales full of knowledge and wisdom, that have been treasured in different places of the world. This article intends to prove the above, through an analysis of "La Mano Peluda" ("The Hairy Hand") which unveils the fact that the text is a dialogue with very old myths: The Greek story about Eros and Psyche; and a story taken from the Indian "Panchatantra", which describes the love between the nymph Urvasi and the mortal Pururavas.

1 Profesor de literatura infantil y coordinador de proyectos de acción social, en esa misma materia, en la Escuela de Formación Docente, de la Facultad de Educación, en la Universidad de Costa Rica, en la División de Educación Básica y en la División de Educación Rural del Centro de Investigación y Docencia en Educación (CIDE), de la Universidad Nacional. También, se ha dedicado a la narración oral. Autor de Queremos jugar (1990), Pedro y su teatrino maravilloso (1993), Escuela de hechiceria, matricula abierta (1996), El libro de la Navidad (2001), La mujer que se sabia todos los cuentos (2003) y Papá es un campeón (2006). 
Con acierto, la Editorial Costa Rica publicó una nueva edición de los Cuentos viejos de María Leal de Noguera. Desde hace muchas décadas, esperábamos esta obra, remozada con ilustraciones ingeniosas, para que las generaciones de hoy y del futuro la puedan disfrutar a plenitud. Se trata de un libro, cuya primera edición, de catorce cuentos, se realizó en 1923 con los cuidados de Joaquín García Monge. La autora incluyó una última nota en 1945 y le aumentó a la colección diez cuentos más.

Se puede considerar los Cuentos viejos, junto con los Cuentos de mi tía Panchita de Carmen Lyra (1920), como textos fundadores de una literatura dedicada a las jóvenes generaciones costarricenses. No es para menos: tanto María Leal de Noguera como Carmen Lyra se formaron como maestras en el Colegio Superior de Señoritas, institución en la que tuvieron como profesor a Joaquín García Monge. Él las influyó profundamente y las instó a escribir historias que existían en la narración oral popular, pues según su propia concepción, esa era la literatura que mejor podían disfrutar los niños: la dicha por el pueblo o la vuelta a contar por los escritores que entienden, de veras, el alma del pueblo.

María Leal de Noguera, en una carta dirigida a García Monge, su maestro y editor, en 1928, confirma que su trabajo es el de recurrir a lo ya dicho, por medio de la palabra hablada:

Desde luego confieso que (los cuentos) no son originales; yo los he recogido de boca de campesinos, los he redactado procurando seguir el orden primitivo de los sucesos y argumentos con un lenguaje comprensivo para los niños. Es lo único que me pertenece (Leal de Noguera, 2004, p. 11).

Resulta llamativo el hecho de que la autora se atribuya el lenguaje como única pertenencia. Y al fin y al cabo, ¿de qué están hechos estos cuentos sino de lenguaje? Es el lenguaje materno que nos nombra, nos da nombre y se convierte en la primera y la última voz que escuchamos. Es el lenguaje popular el que nos forma, nos da las primeras palabras y nos hace sujetos de cultura. Ese es el lenguaje de María Leal, el vernáculo, el materno, regional y global en sí mismo.

María Leal de Noguera nació y desarrolló su vida literaria y profesional en Guanacaste entre 1892 y 1989. Ella misma se hacía llamar en otra carta dirigida a don Joaquín en 1936: "humildísima autora", "maestra de aldea" y "que no sabe de letras". Quizá por esa razón, su obra se ha estudiado poco 
y hasta se ha escuchado decir que sus Cuentos viejos recogen el imaginario popular de su provincia de origen, idea que, a todas luces, es imprecisa y puede perjudicar las múltiples posibilidades de lectura que ofrece el libro, pues tal como lo dice la autora brasileña Ana María Machado (2000): "nunca soy más universal que cuando soy regional".

\section{Con la mirada puesta en Oriente y Occidente}

La escritora guanacasteca no se limitó a elaborar un libro de tradiciones de su provincia natal; por el contrario, creó discursos que establecen múltiples diálogos con manifestaciones culturales griegas, hindúes, latinas, africanas y árabes. Debe apuntarse que este libro se empieza a escribir apenas veinte años después de que la oligarquía cafetalera logra consolidar su posición como una clase hegemónica en el centro de Costa Rica, con una clara tendencia a seguir el modelo expuesto por Sarmiento: lo europeo y exótico como proyecto civilizador y lo interior considerado como barbarie. Álvaro Quesada (1998) lo expresaba como "un discurso doblemente enajenado, en la medida en que se ocultaba su dependencia del otro exterior y reprime la existencia del otro interior". Leal de Noguera nos lo anunció con el propio título del libro: Cuentos viejos, que puede leerse de la misma forma que Cuentos de antaño con sus moralejas, el clásico que el francés Charles Perrault dio a conocer en 1697, en el que aparecen textos universalmente difundidos como Cenicienta o el zapatito de cristal, La Bella Durmiente del Bosque o Maese Gato o el Gato con Botas. Se trata de relatos cuyo origen se desconoce y se remonta a una lejana antigüedad.

Los cuentos de hadas son infinitamente retransmitidos. Vladimir Propp (1987) presentó teorías al respecto que aún hoy son consideradas y valoradas por los tratadistas de los cuentos maravillosos. Para este estructuralista ruso, los cuentos maravillosos se propagaron por el mundo, al igual que el ser humano, y su origen podría situarse en la práctica de viejos ritos de la horda que, en su momento, fueron considerados secretos y sagrados. Propp estudió los ritos de iniciación de diversas culturas (los cuales, en términos generales, presentan la muerte de los niños que renacen, convertidos en adultos) y su relación con cuentos populares, que han pasado de generación en generación, por medio de la oralidad. El mismo Propp sostiene que aunque sus teorías acerca del origen de los cuentos de hadas no pueden ser confirmadas, sus argumentos se apoyan en abundantes pruebas arqueológicas y antropológicas. $\mathrm{Y}$ en lo que parece haber consenso, es que el origen de estos relatos se pierde 
en el tiempo de los tiempos y que emergen reiteradamente en la cosmogonía popular de muy diversas regiones del orbe.

Para Peyrou (1987) otra fuente que nutre los cuentos de hadas son los mitos. El cuento, al igual que el mito, es una estructura simbólica que busca determinar la mentalidad de los individuos, por medio de la promoción de mensajes sobre la familia y el sexo, así como sobre la libertad, la justicia y lo desconocido. Permite, además, cumplir los deseos de éxitos e inmortalidad en los creyentes o lectores que se identifican con los héroes y las heroínas.

Edmond Cros, en su estudio El sujeto cultural. Sociocrítica y psicoanálisis (1997), hizo un acercamiento a los cuentos de hadas, situándolos como textos que resurgen en los discursos, de una manera sutil e imperceptible, como finos rayos que apenas se desdibujan. El autor y el lector no los miran a simple vista, pero saben que los viejos relatos se encuentran allí, como hilos invisibles que se entrecruzan en el tejido textual. Los textos culturales son fragmentos de un intertexto de determinado tipo, que intervienen en la geología de la escritura. De este modo, los cuentos de hadas se presentan como un bien colectivo, cuyas marcas originales de identificación ya se han borrado. A pesar de ello, sus núcleos semánticos se encuentran inalterables.

De esta manera, y desde la perspectiva de Cros (1997), los cuentos de hadas pueden ser considerados un patrimonio o un bien colectivo. Representan un enigma en sí mismos, pues los hilos del texto cultural se presentan con una pregunta, que se contesta, de manera infinita, con otra interrogante. Así, observamos, que en los cuentos de María Leal de Noguera, se pueden visualizar los hilos de otros discursos, cuyo origen podría remontarse al viejo continente, a Oriente y por supuesto, a las culturas precolombinas.

En un artículo más reciente, el estudioso y recuperador de cuentos populares españoles, Rodríguez Almodóvar (2006), sostiene que los relatos maravillosos, narrados y escritos en Europa, comparten las mismas raíces hindúes y europeas, y constituyen un buen ejemplo de diálogo intercultural dado entre pueblos lejanos, así como en pueblos y culturas diferentes. Insiste en que ese vestigio se encuentra oculto en una base cultural indoeuropea. Los cuentos de hadas dialogan constantemente con los mitos griegos y con textos hindúes como el Mahabhárata (siglo V a.C.) y el Panchatantra. Según Padovani (2000), el Panchatantra, libro anónimo, que data de alrededor del siglo VI a.C., es la primera colección de cuentos, conocida en el mundo contemporáneo. Su nombre proviene del sánscrito "pancha", que significa "cinco"y "tantra", que quiere decir "hilo", y precisamente, comprende cinco series de cuentos, que se desprenden del principal. El primer cuento encierra, a modo 
de una madeja de hilo, los cuentos que vendrán después. El Panchatantra fue introducido en Occidente por medio de una versión árabe, titulada Libro de Calila et Dimna, la cual es una especie de novela filosófico-moral, compuesta por apólogos o fábulas, y tiene por protagonistas a dos lobos hermanos, que viven en la corte de un león. La obra fue traducida del árabe al castellano, por Alfonso el Sabio.

El profesor García Monge reafimó la importancia del folklore -y muy especialmente de los cuentos de hadas-en los escritos que dedicó a la literatura para las jóvenes generaciones. Insistía en que los más pequeños conocieran el folklore, lo cual me hace especular -aunque nunca lo sabré con certeza- que mostró a las adolescentes Carmen Lyra y María Leal de Noguera la trascendencia de autores que escribieron fundamentados en la tradición oral del pueblo, como lo hiciera el propio Perrault en Francia, los hermanos Grimm en Alemania, Afanassiev en Rusia o Fernán Caballero en España.

Ese diálogo puede rastrearse en el origen africano de tío Conejo, protagonista de varios de los textos de doña María Leal. Tal como lo afirmó Margarita Dobles (1984), este personaje vino de África y llegó al sur de los Estados Unidos en boca de los negros que fueron tomados como esclavos. Allí, Joel Chandler Harris escribió el libro Cuentos del tío Remus, en el que se sintetizan las lenguas vernáculas africanas con el inglés. Así el conejo africano, llamado Somba, tomó el nombre de Brother Rabbit en Norteamérica. En su viaje por América Latina, se nos transformó en tío Conejo.

\section{Un matrimonio singular: la mano peluda se casa con una niña}

Hacer una lectura minuciosa de los Cuentos viejos implicaría buscar los hilos de la intertextualidad en cada uno de los veinticuatro cuentos que compone la colección. De esta manera, hallaríamos diálogos entre La viejita del sandillal de Leal de Noguera con Tío Conejo y Tío Coyote de Carmen Lyra y con la tradición oral contada en un inglés con acentuados rasgos africanos del Brother Rabbit, narrado por el tío Remus, tal como lo escribió Chandler Harris. En Don Juan del Bijagua de Leal de Noguera, tío Conejo se encarga de convertir a un "pobre muchacho, al parecer un alma de Dios", en un príncipe, valiéndose de embustes y amenazas, de la misma forma que el Gato con Botas lo hace en el cuento del francés Perrault en 1697 o el texto alemán de los hermanos Grimm, de 1814. En el cuento Bienvenido de Leal de Noguera, hay huellas intertextuales del texto Escomponte perinola de Carmen Lyra y al mismo tiempo, del relato El zurrón que cantaba, recopilado por la 
escritora española Fernán Caballero en el siglo XIX. O bien, en La princesa rana de Noguera hay diálogos con La negra y la rubia de Carmen Lyra, argumento que al mismo tiempo observamos en el cuento napolitano Los tres limones, escrito por el francés Eduardo Laboulaye, en sus Cuentos azules que datan de mediados del siglo XIX.

No es posible concentrar en pocas páginas un estudio detenido sobre los textos culturales que atraviesan cada uno de los Cuentos viejos; por eso, centraré mi atención en el texto La mano peluda, en el cual se puede leer, de manera diáfana, la inscripción de dos mitos, el griego referente a Eros y Psique, así como el hindú, que cuenta la historia de la ninfa Urvasi y su marido, el mortal Pururavas.

Estudiemos, primero, el caso griego. Tal como lo contó el latino Lucio Apuleyo, en su obra Metamorphoseon libri XI (Asinus aureus), narración de las aventuras sobre un joven convertido en asno; en el transcurso de la acción se insertan varias historietas y digresiones, entre ellas, la conocida narración de Psique y Eros.

Mas, antes de que Apuleyo la narrara, ya existía una versión oriental referente al mito de Eros y Psique. Los hindúes la conocieron como el mito de la ninfa Urvasi y el mortal Pururavas, tal como lo refiere Rodríguez Almodóvar (2006). Este mito aparece en el Rig Veda, x 95 (aproximadamente

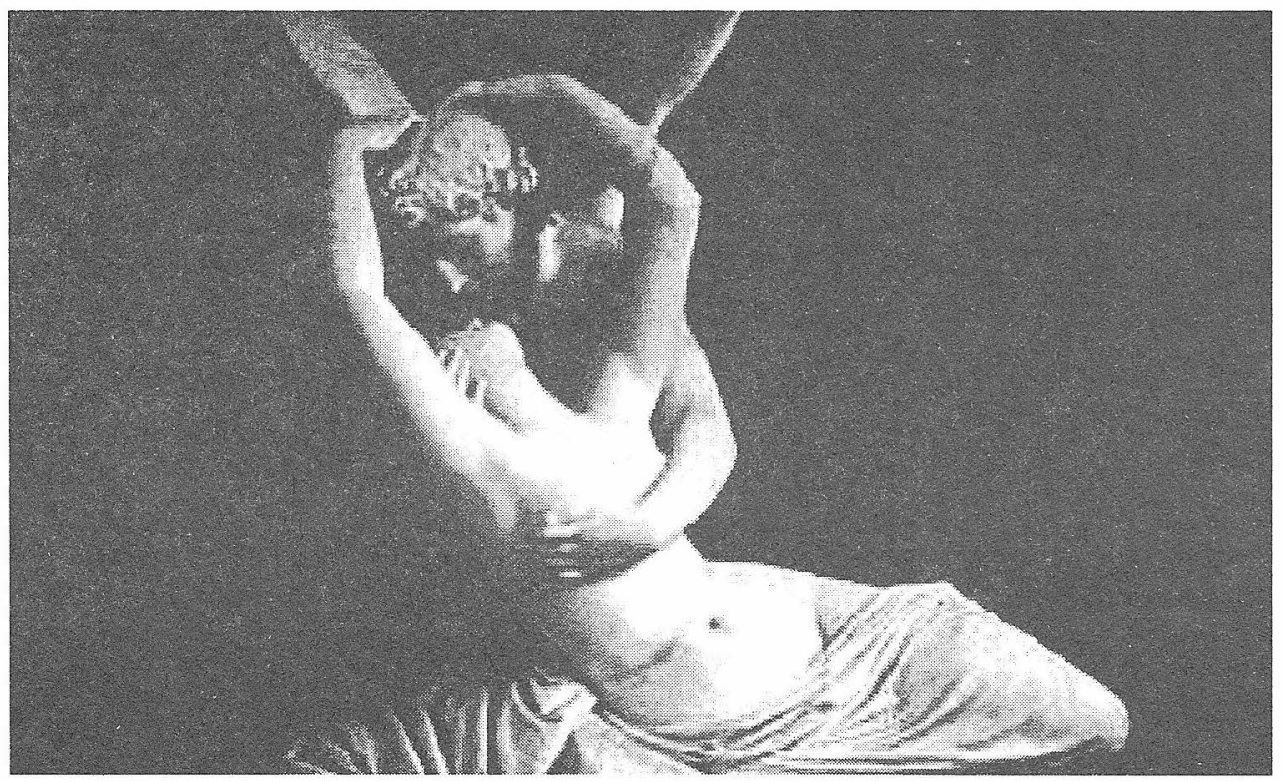


hace unos 3500 años), así como el quinto libro del Panchatantra (V, 8). Hay referencias de él en el Somadeva (III, 17) y en el Satapatha Brahmana (V, I).

Bettelheim (1975), en su estudio psicoanalítico sobre el cuento de hadas, observa el mito de Eros y Psique como un antecesor del difundido cuento La Bella y la Bestia, del cual existen múltiples versiones. Una de las más conocidas en Occidente fue la que la profesora francesa, Jeanne-Marie Leprince de Beaumont publicó en 1756, en uno de los cuatro volúmenes de su obra didáctica:

Almacén de los niños o diálogos de una institutriz con sus distinguidos alumnos, en los que se hace pensar, hablar y actuar a los jovencitos según el genio, temperamento y las inclinaciones de cada cual. Represéntense los defectos propios de su edad y muéstrase el modo de corregirlos; aplicase el autor tanto a formar el corazón como a ilustrar el espiritu. Contiene un resumen de Historia Sagrada, de Mitología, de Geografia, etcétera, con multitud de reflexiones útiles y cuentos morales para propiciarles delicado solaz; todo ello escrito en un estilo sencillo y adecuado a la ternura de sus almas.

Tal como lo dice la crítica cubana Alga Marina Elizagaray (1981): "De no haber escrito también "La Bella y la Bestia" no la recordaríamos con simpatía y sólo se le citaría por el enorme y variado surtido de ese almacén" (p. 60). Tal vez esto ocurra porque, con el cuento de la doncella atrapada dentro del castillo del monstruo, la severa institutriz se dejó llevar por el influjo de las hadas. De la misma forma, Leal de Noguera olvidó los preceptos didácticos, la intención pedagógica y se dedicó a gozar el relato de la dulce muchacha que duerme al lado de su ominoso marido: la mano peluda.

Para descubrir los hilos intertextuales en La mano peluda, es necesario conocer el cuento de Urvasi y Pururavas, tal como lo cuenta Rodríguez Almodóvar (2006).

La ninfa Urvasi amaba profundamente al mortal Pururavas. Se casó con él y le advirtió: "Tres veces al día te abrazarás a mí. Pero nunca te acostarás conmigo contra mi voluntad y jamás te dejarás ver por mí desnudo". Vivían, llenos de felicidad, pero los ganhdarvas ${ }^{2}$, consideraron que la pareja ya había permanecido en unión mucho tiempo y creyeron que debían apartarlos. Urvasi poseía una oveja con dos corderitos, atados a la cama y los ganhdarvas se los

2 Divinidades menores, que rigen los caballos del sol, según Borges y Guerrero, 2005. 
robaron. El hombre se levantó, sin ropa alguna, de la cama y fue iluminado, sorpresivamente. La ninfa vio la desnudez de su esposo y expresó: "He de desaparecer con el primer amanecer. Vete, Pururavas, a tu casa, porque yo soy como el viento, difícil de coger". El hombre lloró, desconsolado, por mucho tiempo. Y Urvasi, conmovida, se le apareció y le dijo: "Ven conmigo la última noche del año. Te acostarás conmigo y entonces nacerá nuestro hijo". Pururavas cumplió con este pedido y encontró un palacio de oro donde se hallaba su esposa. Ella le recomendó: "Mañana los ganhdarvas van a concederte un deseo. Tú dirás lo que deseas". "Di tú mi deseo", pidió Pururavas. "Di que te permitan ser uno de nosotros para que te quedes conmigo", expresó Urvasi. Todo se cumplió de esta manera, y los ganhdarvas le dieron un poco del fuego sagrado de los sacrificios y se convirtió en un ser celestial, al igual que su esposa, Urvasi.

En el mito griego, el de Eros y Psique, un matrimonio engendra tres hijas. Una de ellas, Psique, es tan hermosa que la diosa Venus siente celos y la condena a casarse con un monstruoso marido. En el texto costarricense, tenemos a un viejecito que tiene tres hijas y decide casarlas "al primero que pidiera su mano y por orden de edad". Las dos mayores se unieron en matrimonio con señores muy ricos, pero la menor convivía contenta con su

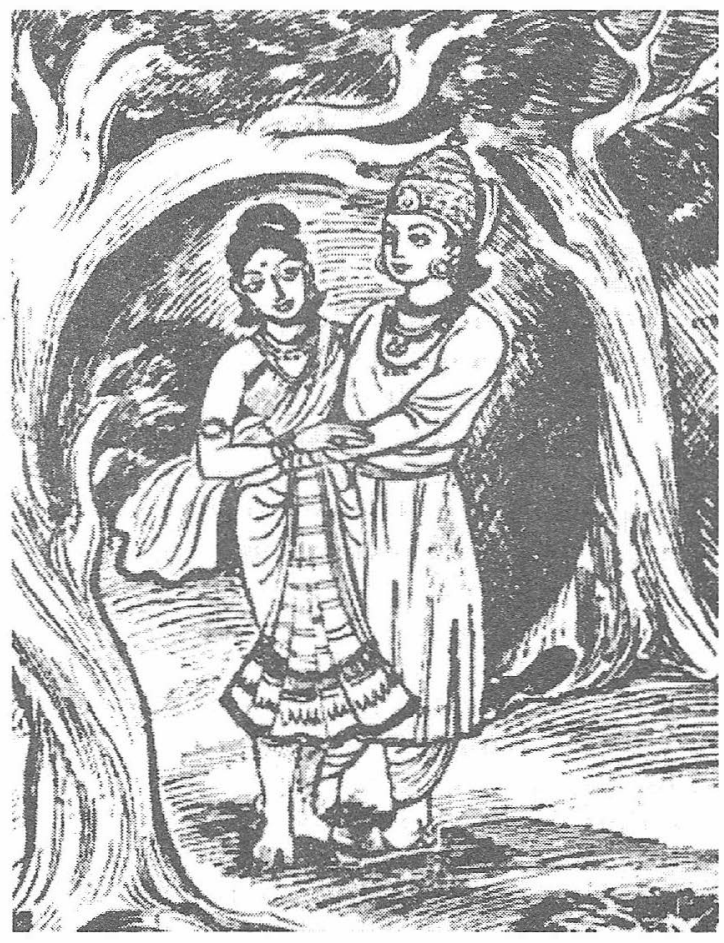
anciano padre.

En el mito, Apuleyo describe que Eros, por encargo de su madre Venus, acude a matar a la doncella, pero termina pinchándose con una de sus propias flechas y, como consecuencia, se enamora de la que iba a ser su víctima. Psique es abandonada en un palacio en el alto pico de una montaña. Allí, Eros se presenta por las noches. Llega en la oscuridad y se anuncia como un monstruo repugnante que no puede alcanzar a ser visto por nadie. En el cuento de Leal de Noguera, una mano peluda aparece pegada al cielo raso de la casa y 
pide al padre casarse con la hija menor. Como el anciano había empeñado su palabra, entrega a la pobre muchacha, la cual es llevada a un palacio perdido en medio de un bosque.

El viento se encarga de transportar a Psique y a la doncella del cuento costarricense al misterioso castillo. El mito griego narrado por el autor latino habla de un viento del Oeste que la levanta y la conduce hasta un valle florido donde hay un palacio de marfil y columnas de oro. En el caso de Leal de Noguera, la Mano Peluda anuncia que su prometida será llevada primero por una brisa suave y olorosa, después aparece un viento fuerte que riega de flores el camino y, por último, una tempestad la eleva como una pluma y la traslada montada encima de una nube. Viento y flores en ambos textos sirven como medio de transporte.

Al llegar al palacio, tanto Psique como la jovencita del cuento escuchan música, interpretada por seres que no pueden ser vistos. Apuleyo nos dice:

Un dulce coro llenaba el aire con su música y suaves voces de seres invisibles musitaban en su oido:

-Todo esto es tuyo (Pope de Osbome, 1995).

La protagonista del cuento La mano peluda, al penetrar en el palacio, escucha acordes de una música divina, que hace pensar en la gloria celestial. Una voz en tono amable le dice: "Hermosa joven, ven a saciar tu apetito con esos manjares; este palacio y todo lo que hay en él es tuyo".

Eros llega por la noche donde Psique y le hace saber que es su esposa. "Te amo más que a nada en este mundo (dice el dios), pero debo pedirte que nunca trates de mirar mi rostro. Sólo te visitaré en las noches, las cuales serán gloriosas y llenas de felicidad". En el cuento de la autora guanacasteca, no hay intercambio de palabras entre marido y mujer, pero la muchacha y la Mano Peluda comparten el lecho. Se dice literalmente:

...se acostó en la misma cama y sintió que a su lado se acostó un animal semejante a una oveja; le dio mucho miedo y quiso huir, pero ¿cómo? No había luz y todo estaba atrancado (Leal de Noguera, 2004).

De la misma forma, según Rodríguez Almodóvar (2006), el mito hindú hace referencia a la ninfa Urvasi, quien amaba profundamente al mortal Pururavas. Cuando se casó con él, le dijo: 
Tres veces al día te abrazarás a mí. Pero nunca te acostarás conmigo contra mi voluntad y jamás te dejarás ver por mi desnudo (Rodríguez Almodóvar, 2006).

Como se observa, en el mito hindú existe el mismo sentido de la prohibición tangible en el mito griego y en el cuento de Leal de Noguera: la prohibición de ver al esposo, quien yace al lado, en la misma cama, ya sea porque es un monstruo que no puede dejarse mirar, o porque una ninfa no puede ver, en la desnudez, a un mortal.

Es la envidia y las murmuraciones de las hermanas de Psique -en el momento en que llegan al palacio- las que hacen que la doncella termine decidiéndose por encender una lámpara de aceite y mirar el rostro de su desconocido esposo mientras este duerme. Psique, además, sostiene un puñal en la mano para asesinarlo. Las hermanas la han convencido de que la matarán apenas engendre un hijo del monstruo. Para su sorpresa, al colocar la luz cerca de su esposo, esta se deslumbra ante sus atributos físicos. Tanto así que no se da cuenta de que deja derramar una gota de aceite sobre su hombro. Eros despierta y al notar que su mujer intenta matarlo, se lamenta:

- ¿Amor mío, tenías miedo de que yo fuera un monstruo horrible?

Y antes de que Psique pudiera responder, dijo:

-No puede haber amor si no hay confianza... (Pope de Osborne, 1995).

Y se va dejando a su esposa sumida en la angustia. Así que Psique busca a Venus, madre de su amado, y cumple cuatro peligrosos trabajos.

En el mito hindú, también se observa la separación de la pareja. La ninfa Urvasi y el mortal Pururavas viven felices largo tiempo. Pero los ganhdarvas consideraron que la divina Urvasi ya había pasado suficiente tiempo con un mortal, y decidieron apartarla del mundo y de su marido. Los ganhdarvas sabían que Urvasi mantenía a una oveja y a dos corderitos atados a su cama y, en la oscuridad, fueron robándose cada uno de los animales. Cuando hurtaron el segundo, Pururavas se levantó para dar castigo a los ladrones. Los ganhdarvas lanzaron rayos de luz y la ninfa Urvasi miró, por primera vez, la desnudez de su marido. Ella le dijo:

He de desaparecer con el primer amanecer. Vete, Pururavas, a tu casa, porque yo soy como el viento, dificil de coger: Me has desobedecido (Rodríguez Almodóvar, 2006). 
El hombre llora, pero sus lágrimas no le sirven de nada. Ve alejarse, en el aire, a su amada.

En el cuento costarricense, un hada anciana le entrega a la muchacha una candela y una caja de fósforos. "Cuando te acuestes y calcules que el animal esté dormido, enciende la candela”, la aconseja. La joven cumple con el encargo y a la luz de la vela, se encuentra con un bello joven con rostro de ángel. Es tanta su admiración que deja caer tres gotas de cera en la frente del joven, el cual se despierta al momento.

En el mito griego, cuando Psique termina sus cuatro trabajos, cae en un sueño profundo. Eros la despierta con un beso y la lleva donde Zeus, el cual los une en matrimonio. Años después, tienen una hija llamada Dicha. En el cuento de Leal de Noguera, hallamos que la joven se desvanece ante la belleza de su esposo, este la despierta con un beso y le dice: “¡Niña hermosa, tú me has salvado...! ¡Yo soy el Príncipe de la Dicha; en mi palacio que hoy también es tuyo, viven todas las dichas del mundo!'. El cuento termina cuando las hermanas y el viejo padre de la muchacha se van a habitar en el hermoso Palacio de la Dicha.

Felicidad, dicha..., en ambos textos se entrelazan el amor y la confianza en un diálogo en el que median, aproximadamente, un abismo de veinte siglos.

En el mito hindú de Urvasi y Pururavas, también se llega a una solución que satisface las necesidades de la pareja. El mortal Pururavas llora desconsoladamente y su esposa, la ninfa, termina conmoviéndose. Le dice: "Ven conmigo la última noche del año. Te acostarás conmigo entonces y nacerá nuestro hijo" (Rodríguez Almodóvar, 2006). El hombre cumple el pedido de su mujer y al llegar descubre un maravilloso palacio de oro. Los ganhdarvas le piden que entre y allí encuentra a la amada Urvasi, quien le advierte: "Mañana los ganhdarvas van a concederte un deseo. Tú dirás lo que deseas". El mortal no sabe qué pedir y le pide consejo a la ninfa. Ella insiste: "Di que te permitan ser uno de nosotros para que te quedes conmigo".

Los ganhdarvas le dieron un poco del fuego sagrado, con el cual hizo sacrificios y se convirtió en un ganhdarva, un ser celestial, digno de amar a Urvasi.

Debe anotarse que tanto en el mito de la India como en el de Grecia, ocurre el nacimiento de un niño como muestra de felicidad. Urvasi invita a Pururavas a acostarse junto a ella, pues así nacerá su hijo. En el texto occidental, Psique y Eros sellan su amor con el nacimiento de su hija, que tiene por nombre Dicha o Felicidad. Ambos nacimientos implican la madurez y el 
equilibrio de la pareja: Psique es el alma, la razón, el pensamiento y Eros, el erotismo, la pasión y la carnalidad. Ese vínculo entre razón y pasión es el amor en sí mismo, la llama doble, la plenitud de la mente y el cuerpo, la razón de ser de los amantes.

Aunque no haya ninguna invocación a un hijo, en La mano peluda de Leal de Noguera, crepita la llama doble de la razón y el erotismo. La protagonista: la niña buena -de quien nunca sabemos el nombre- es el pensamiento, la razón, el alma -al igual que Psique y Urvasi-. Mientras que, la Mano Peluda es el misterio del erotismo que surge de las sombras, es el animal, que semejante a una oveja, se desliza bajo las sábanas hasta palpar el virginal cuerpo de la niña, es la figura deforme cubierta de vello, el misterio que invoca lo desconocido, lo genital, que primero perturba y luego, se convierte en placentero.

Al igual que en el mito griego, en el cuento La mano peluda, se da la presencia de la luz redentora. Psique enciende una lámpara de aceite, y la niña buena del cuento de Leal de Noguera hace lo mismo con una candela y una caja de fósforos. En el mito hindú, los ganhdarvas entregan un poco del fuego sagrado. Fuego, lámpara de aceite y candela: es la luz que permite encontrar la belleza que se esconde detrás de lo que se podía considerar monstruoso. Es la luz a la que sólo se puede llegar con la paciencia y la tenacidad. Tal vez sea la luz de la sabiduría de los cuentos. Saber que se encuentra en la boca de muchos hombres y mujeres que nunca se encubrieron con ropajes académicos. Este es el saber de los pueblos, lo que también podríamos llamar la "docta ignorancia".

Y como suele ocurrir con los cuentos de hadas, la historia nunca se puede dar por concluida. Ana Victoria Garro, narradora oral y artista plástica, también percibió el encanto con que Leal de Noguera escribió la historia de "La mano peluda", por eso ella realizó una nueva versión de ese texto, y la presentó en un espectáculo y en disco compacto llamado Un miedo maravilloso. Leyendas de la tradición oral costarricense (2005). En esta versión, el cuento, en los inicios del siglo XXI, tomó otras proporciones, pues la niña buena ya tiene nombre, se llama Ester; y ella, más que alegrarse por observar la transformación de la ominosa mano en un apuesto marido, se lamenta. Ester camina alrededor del lecho matrimonial, en la madrugada, con una vela. Y espera que el hombre se transforme de nuevo en la mano peluda. Se observa, de esta manera, que la mujer, que ya es dueña de su nombre, también es propietaria de la expresión de su sexualidad, y no teme en manifestar su pasión 
por lo que, en otros tiempos, le resultaba truculento, atrayente y erótico: el esposo monstruo, la temida mano.

De esta forma encontramos en Cuentos viejos los hilos intertextuales de dos mitos, el griego y el hindú. Los múltiples lectores, niños y adultos, podrán encontrar, de manera imperceptible e inconsciente, los fragmentos de un cuento, que más que regional y nacional, tiene resonancia en los discursos literarios de otras geografias.

Sin embargo, aún falta mucho por descubrir. Habría que estudiar la presencia de culturas árabes, africanas u otras culturas orientales. Son los lectores los que tienen la palabra ahora. Lectores niños y niñas -que también viven dentro de los adultos-, que puedan conocer, ampliar y descubrir muchas formas de recorrer estos cuentos viejos que siempre son nuevos. Son textos que sentimos familiares y cercanos, a pesar de que su origen se pierde, se difumina en remotas culturas y lejanas tierras. Son cuentos que, de manera imperceptible, nos conducen a un interminable diálogo con el universo. 


\section{Referencias}

Bettelheim, B. (1990). Psicoanálisis de los cuentos de hadas. Barcelona: CRÍTICA. Borges, J. y Guerrero, M. (2005). El libro de los seres imaginarios. Madrid: ALIANZA.

Caballero, F. (1988). Cuentos de encantamiento. Madrid: ESPASA-CALPE.

Cros, E. (1997). El sujeto cultural. Sociocrítica y psicoanálisis. Buenos Aires: CORREGIDOR.

Dobles, M. (1984). Costa Rica. Panorama de la literatura infantil en América Latina.

Elizagaray, A. (1981). Niños, autores y libros. La Habana: GENTE NUEVA.

Garro, A. (2005). Un miedo maravilloso. Leyendas de la tradición oral costarricense. (Disco compacto). San José: UNIVERSIDAD FEDERADA SAN JUDAS TADEO.

Goldin, D. (2000). "Ana María Machado: encuentro con la red". Espacios para la lectura, 14-15.

Laboulaye, E. (1998). Cuentos azules. Madrid: MONTENA.

Leal, M. (2004). Cuentos viejos. San José: EDITORIAL COSTA RICA.

Leprince de Beaumont, Jeanne-Marie. (1992). La Bella y la Bestia y otros cuentos. Madrid: GAVIOTA.

Padovani, A. (2000). Contar cuentos. Desde la práctica hacia la teoría. Buenos Aires: PAIDÓS.

Perrault, Ch. (1987). Cuentos de antaño. Madrid: ANAYA.

Peyrou, O. (1987). "Introducción a los cuentos de hadas: la iniciación y la muerte". Perrault Cuentos de antaño. Madrid: ANAYA.

Pope, M. (1995). Mitos griegos. Bogotá: GRUPO EDITORIAL NORMA.

Propp, Vladimir. (1987). Las raices históricas del cuento. Madrid: EDITORIAL FUNDAMENTOS.

Quesada, A. (1998). Uno y los otros. Identidad y literatura en Costa Rica 18901940. San José: EDITORIAL DE LA UNIVERSIDAD DE COSTA RICA.

Rodríguez, A. A. (2006). "Entre Europa y la India. Las raíces comunes de los cuentos populares". Cuadernos de Literatura Infantil y Juvenil (CLIJ), 19 (195), 7-14.

Rubio, C. (2001). Por la tierra de las hadas: Perrault, Leprince de Beaumont, Grimm y Andersen. San José: URUK.

Seijo, M. (1996). "Érase una vez dos hermanos". Cuadernos de literatura infantil y juvenil, 9 (88), 8-24. 